\title{
La romería de Zapopan. Renovación permanente de nuestro pasado indio.
}

Zapopan's pilgrimage. Permanent renewal of our Indian past.

\section{Lourdes Celina Vázquez Parada}

Centro de Estudios Religión y Sociedad. Universidad de Guadalajara (MÉXICO)

CE: Icelinavp@gmail.com / ID ORCID: 0000-0002-3288-7190

DOI: $\underline{10.32870 / \text { sincronia.axxiv.n77.25a20 }}$

Esta obra está bajo una Licencia Creative Commons Atribución-NoComercial 4.0 Internacional

BY.NC

Recibido: 22/08/2019

Revisado: 15/10/2019

Aprobado: 08/11/2019

\section{RESUMEN}

Este ensayo analiza la historia de la romería más grande de México, a la Virgen de Zapopan, que se realiza el día 12 de octubre de cada año. Participan 65000 danzantes y alrededor de un millón ochocientos mil peregrinos, quienes la acompañan de regreso a su basílica después de que ha visitado todas las parroquias de la ciudad vecina de Guadalajara. Esta tradición se ha mantenido desde el siglo XVIII como una reivindicación de la importancia del occidente de México frente a las políticas de centralización a lo largo de la historia. Muestra, además, cómo en una región donde la población indígena fue diezmada durante la Colonia y sus habitantes se sienten orgullosos de su identidad criolla, en las tradiciones religiosas populares florecen las huellas de ese pasado indígena que no se logrará borrar, porque es parte fundamental del mestizaje de la población mexicana, su tradición y su cultura.

Palabras clave: Romería de Zapopan. Identidad mexicana. Danzas indígenas. Historia de Jalisco. Religiosidad popular. 


\section{ABSTRACT}

This essay examines the history of Mexico's largest pilgrimage, to the Virgin of Zapopan, which takes place on October 12 of each year. 65,000 danzantes and about three million pilgrims participate, who accompany her back to her basilica after she has visited all the parishes of the neighboring city of Guadalajara. This tradition has been maintained since the 18th century as a vindication of the importance of western Mexico in the face of centralization policies throughout history. It also shows how in a region where the indigenous population was exterminated during the Colony and its inhabitants are proud of their Creole identity, in popular religious traditions the traces of that indigenous past that will not be erased are flourished, because it is a fundamental part of the mestizaje of the Mexican population, its tradition and its culture.

Keywords: Zapopan Pilgrimage. Mexican identity. Indigenous dances. History of Jalisco. Popular religiosity.

\section{La romería de la Virgen de Zapopan}

Es octubre. En el occidente de México, donde el temporal de lluvias termina en septiembre y se seca día a día el lago más grande del país, casi todos los años aparece como por milagro la última tormenta en la víspera de la romería de la Virgen de Zapopan, la madrugada del día 12. Ya es común que la jerarquía diocesana lleve en los meses previos a la imagen taumaturga a visitar las comunidades ribereñas para solicitarle lluvias abundantes que devuelvan a Chapala su antiguo esplendor.

Sin embargo la virgen de la Expectación, declarada desde el siglo XVIII "protectora contra los rayos y tormentas" ha cuidado que las lluvias no resten importancia a su fiesta. El día 8, acompañada por danzantes y peregrinos, la imagen recorre el último trayecto entre los dos templos más cercanos a la catedral de Guadalajara, donde pasará la última noche de su visita anual: va de Santo Domingo de Guzmán a Santa Elena. Las calles que recorre están adornadas con lazos de papel picado de colores azul y blanco, los colores de la virgen, a los que se ha añadido el amarillo, color del Vaticano, en los años recientes. A cada 50 metros se coloca un arco de flores de donde pende una granada con confeti 
y pétalos de flores, la cual se abre al paso de la imagen. El piso está alfombrado con alfalfa y aserrín. La gente la espera desde muchas horas antes a las puertas de sus casas. Colocan altares con sus imágenes preferidas, las cuales, según la creencia popular, resultarán bendecidas al paso de la zapopana.

Son las cuatro de la tarde y no hay nubes negras que ensombrezcan esta algarabía contagiosa. Los niños, recién bañados y vestidos de fiesta, juegan en la calle a la espera del momento tan ansiado de ver a la virgen de cerca. Recorremos el trayecto adornado captando imágenes. Un muchacho tatuado escribe en el piso con aserrín de colores "Bendice nuestro barrio". Le pido permiso para tomarle una foto y pregunta ¿a mí o a la banda? A la banda, si quieren. Y viene la banda muy contenta a retratarse detrás de aquella súplica. Son los chavos rebeldes del barrio que se embriagan y tal vez delinquen, pero que se suman a la romería y piden la bendición. Son conocidos y reconocidos por los vecinos. También frente a ellos la imagen se detiene y los bendice. Junto a estos arcos se instalan las personas enfermas o necesitadas de alguna gracia, para aprovechar el instante en que el cortejo se detiene y la imagen se baña de confeti; la gente se acerca y toca con toda su fe el capelo de cristal que la protege.

La procesión inicia con los danzantes de la parroquia. Su atuendo consiste en camisa y pantalón de color gris a los cuales se cuelgan tiras de color café para semejar el traje de los apaches. Al frente va el "diablo" abriendo paso al cortejo, seguido de la escolta de danzantes con el estandarte de santa Elena. La danza tiene decenas de miembros que bailan al son de los tambores. En sus zapatos clavaron láminas de metal para hacer música con sus pasos.

Le sigue la banda de guerra. Son muchachos y muchachas vestidos con uniforme azul y blanco, que desfilan a paso redoblado y con repiques de trompetas y tambores. En el cortejo nunca faltan los miembros de la Guardia de honor de la virgen. Este fervoroso y disciplinado contingente se compone de señores, jóvenes y niños; y también de señoras, muchachas y niñas. Cada grupo lleva su estandarte. Los hombres de la Guardia sujetan unos gruesos cables que separa al contingente de los espectadores. Del calabrote interior se jala la camioneta que traslada la imagen, y del exterior, se 
cuelgan los miles de peregrinos que la acompañan y se quieren sentir cerca de ella. Quien ha logrado poner su mano en la gruesa cuerda, difícilmente la soltará antes de llegar al fin del trayecto.

Al paso de la imagen la gente aplaude, grita vivas, alza a los niños en hombros, pide favores, llena su vista con la imagen y reza fervorosa. El contingente se cierra con la banda de música de la parroquia, que entona el tan conocido tema de Tropas de María: "Tropas de María/ sigan la bandera/ no desmaye nadie/ vamos a la guerra/ vamos a la guerra..." herencia de ese pasado cristero que se marcó en la conciencia regional de los habitantes del occidente de México.

Llueve y sigue Iloviendo. Las tormentas en Jalisco se anuncian con truenos y centellas. Es 10 de octubre y la imagen de la virgen de Zapopan ya vela en la catedral metropolitana. Casi al atardecer cae en toda la ciudad una fuerte granizada. Los vientos soplan con fuerza y derriban árboles viejos por las calles de la ciudad. Las avenidas se inundan y bloquean. El tráfico se congestiona. Millones de canicas de hielo caen por toda la ciudad golpeando a los transeúntes, los toldos de los carros, los vidrios de las ventanas. Es, al principio, una granizada sin lluvia. Los sonidos del golpeteo del hielo se acompañan con relámpagos que iluminan la ciudad y preceden al trueno. Luego viene la lluvia. Primero en grandes gotas, para continuar durante toda la noche con una llovizna fina. La imagen taumaturga está protegida en el altar mayor de la catedral y es visitada por miles de fieles.

La lluvia continúa por las noches. La virgen protege a sus devotos durante los trayectos. Se teme un fuerte aguacero para el 12 de octubre, "día de la raza", día de "la llevada". La tarde del 11 se celebra la misa de despedida en la explanada del Hospicio Cabañas, en el corazón de la ciudad. Es la misa donde el cardenal despide a la imagen para que regrese a su casa al cuidado de los frailes franciscanos. A ella se invita, en primer lugar, al clero diocesano y los seminaristas y se les reserva un lugar especial. El cardenal y sus obispos auxiliares concelebran en un estrado montado ex profeso. Se invita a los medios, se colocan altavoces por todas las plazas cercanas y se predica insistentemente a creyentes y no creyentes. En la plaza principal de la ciudad ondea la bandera del Vaticano y se repiten a todo volumen mensajes previamente grabados. Desde hace algunos años se relegó a los contingentes de danzantes en este día. Ellos no aparecen. Llegan hasta el anochecer y velan en los portales, esperando que despunte el alba para iniciar sus danzas. 
12 de octubre. A las dos de la mañana cae una tormenta que baña a la ciudad y cede, casi milagrosamente, a las 4. En ese momento se empieza a escuchar por toda la ciudad el retumbar de los tambores. Las danzas inician y anuncian el alba. Saludan al amanecer, saludan a la virgen que todavía está guardada en el altar de la catedral. A las cinco vuelve el silencio. Es la hora de la misa de despedida; y a las seis vuelve a escucharse, ahora sí ininterrumpidamente, el retumbar de tambores y el sonido de los caracoles; las trompetas y los pasos acompasados de los danzantes. La música despierta a la ciudad antes del amanecer. Familias enteras recorren las calles para alcanzar la romería. Miles, decenas de miles de personas, durmieron en las banquetas apartando un lugar privilegiado. En la avanzada están cerca de cien contingentes de danzantes que recorren los siete y medio kilómetros del trayecto al ritmo de sus sonajas, de sus tambores, de sus caracoles. Muchos peregrinos caminan descalzos y con los pies hinchados. Madres cargando en brazos a sus hijos pequeños. Ancianos en sillas de ruedas. Mujeres y niños, jóvenes y adultos.

Horas después el entusiasmo contagioso de las danzas se detiene para dar paso a los contingentes de fieles fervorosos de las parroquias que preceden a la imagen rezando aves marías. En la parte central del contingente los estudiantes de los seminarios diocesanos avanzan ordenadamente "animando" con el rezo del rosario y la larga letanía. Como parte de esta "animación" oficial avanza el único carro alegórico que publicita al periódico de la diócesis y sus estaciones de radio y televisión.

Ya se ve el carro de la virgen. Se escucha la banda de guerra que precede a los altavoces con el rezo del rosario -otra vez- porque la jerarquía quiere quitar el carácter profano a la fiesta. Dice estar en contra de los sincretismos. El carro de la virgen se adorna con temas relevantes del momento: a veces hace alusión a los mártires cristeros o a las apariciones de Guadalupe al santo Juan Diego. En este país donde el desarrollo se ha concentrado en la región central, la guadalupana es la imagen del centro; la zapopana, la del occidente del país. Es la representación de la lucha entre centralismo y federalismo en la historia de México.

Detrás de ella vienen los pajareros. Son personas que cargan a sus espaldas jaulas con cenzontles y ruiseñores que le cantan a la virgen durante el trayecto. Luego otra vez el sonido de los 
cascabeles y el tun tun de los tambores. De nuevo el ambiente festivo de las danzas y los millones de observadores que hacen valla a lo largo del recorrido; la multitud que sabe que no llegará a la basílica no por falta de fuerzas, porque la fe les da fuerza, sino simplemente porque no cabe nadie más en ese espacio que falta aún por recorrer.

\section{Breve historia de la tradición}

La imagen de la virgen de la Expectación, o de Zapopan, fue elaborada en el siglo XVI por artesanos indígenas de Michoacán, con una pasta de caña de maíz. Esta imagen es similar a otras que se veneran en los santuarios del occidente de México, como san Juan de los Lagos o Talpa, y llegó a la Nueva Galicia en 1530, colgada al pecho de fray Antonio de Segovia: Al terminarse la guerra del Mixtón, con la pacificación promovida por fray Antonio de Segovia, explica Sánchez "les dejó en donación la imagen de Nuestra Señora de la Inmaculada Concepción, que, colgada al cuello, durante cerca de doce años había traído consigo" (Sánchez, 2018, p. 205).

Cuenta la historia que en todas las expediciones de conquista, al lado del ejército español viajaba siempre un religioso, tanto para atender espiritualmente a los expedicionarios, como para bautizar a los naturales; y que su presencia era indispensable para asegurar el adoctrinamiento de los pueblos. Este requisito fue impuesto por la Corona española a fin de considerar verdaderamente sometidos los territorios conquistados. La época más peligrosa para los misioneros franciscanos fue la gran rebelión de 1540, cuando los nativos caxcanes del occidente de México decidieron atacarlos, dado que ya los habían identificado plenamente con los soldados conquistadores (Muriá, 1980). Esta "fue la más terrible de las sublevaciones indígenas de toda la época colonial, cuya sofocación requirió, como se sabe, de la participación de todo el aparato represivo del virreinato." (Muriá, 1980, pp. 3567)

El santo Santiago se "aparecía" por todas partes en defensa de sus protegidos, los conquistadores. Según relatan las crónicas de la época, les ayudaba a ganar todas las batallas en contra de los decididos nativos. (Cardaillac, 2002) A la espada de los soldados se unía la cruz de la evangelización. La espada y la cruz fueron los símbolos de la conquista que se resolvió a favor de los 
españoles, masacrando y destruyendo los pueblos de indios. Luego de haber sido vencidos, sometidos y diezmados, el Apóstol de Nueva Galicia, fray Antonio de Segovia, les entrega la imagen de la virgen de la Expectación que portaba en su pecho, para que les consuele y alivie. Así se "pacificó" a la región, y desde entonces la virgen de Zapopan es llamada la Pacificadora.

Fray Antonio de Segovia continuó con su obra misionera recorriendo el extenso territorio de la Nueva Galicia. Fundó diversos hospitales y conventos dedicados a la advocación de la Inmaculada Concepción, que fueron una gran ayuda para la población en los tiempos de pestes y epidemias. Durante los siglos XVII y XVIII, la imagen quedó bajo resguardo de diferentes sacerdotes sin tener un lugar fijo. En 1819 el obispo Juan Ruiz de Cabañas y Crespo la entrega formalmente en custodia a la orden de los religiosos franciscanos, reconociendo así la importante labor que habían desarrollado a lo largo de la historia colonial. Esto implicaba el requerimiento de construir una iglesia que pudiera albergarla, y se procede a la edificación de la parroquia de san Pedro en lo que ahora es el corazón de la cabecera municipal.

Fue hasta las primeras décadas del siglo XIX cuando, gracias al financiamiento económico de una monja contemplativa de la Orden de Santa Mónica, la Madre Manuela, se construyen el convento franciscano de Zapopan y el santuario que desde entonces alberga la imagen de la virgen. En 1819 se conformó el Colegio Apostólico con religiosos procedentes de Guadalupe, Zacatecas, teniendo como sede este nuevo convento y como objetivo la formación de misioneros.

Desde que la imagen de la virgen de la Expectación fue entregada por fray Antonio de Segovia a los indígenas sometidos para su veneración y custodia, éstos se la apropiaron como símbolo de consuelo y así la siguen venerando hasta la fecha. Por eso la romería ha mantenido a lo largo de los siglos ese carácter de festividad indígena como rasgo peculiar e irrenunciable; como rasgo indiscutible de la religiosidad popular no impuesto por los clérigos ni por la institución eclesial.

En la historia de esta tradición, casi desde su origen, y "por diversos caminos, la devoción a la Virgen de Zapopan se afirmaba como símbolo religioso y civil de la nueva síntesis cultural cristiana que se fraguaba lentamente en la Nueva Galicia". (González, 1999, pág. 8) La imagen ya visitaba la ciudad de Guadalajara desde 1693; particularmente en 1721 con motivo de las epidemias que 
azotaron a la región. Esta visita anual a la ciudad episcopal de Guadalajara se formaliza en 1734 con acuerdos entre el Cabildo Eclesiástico y el Ayuntamiento de Guadalajara, donde el poder civil "se obliga a costear los gastos que se originen con motivo de las procesiones que a su llegada y despedida se tendrán, así como los gastos derivados durante el novenario que se le hará en la catedral." Esto se encuentra en el documento Reglamentos, ordenanzas y disposiciones para el buen gobierno de la ciudad de Guadalajara, 1733-1900" (González, 1999, p. 14-15). El cumplimiento se suspende durante las etapas de guerra civil en el siglo XIX; se retoma posteriormente y se cumple hasta la fecha, ya que las autoridades políticas civiles siguen apoyando con los gastos y vigilancia de la multitudinaria peregrinación.

La romería a Zapopan es la fiesta que ha convocado a todos los sectores de la sociedad y todas las clases sociales. Las decenas de miles de danzantes provienen de las colonias de clase media, clase baja y sectores en situación de pobreza. Las parroquias en que se venera y festeja con mayor alegría son las de colonias populares. Los vecinos de colonias de clase alta asisten como espectadores al colorido espectáculo que ofrecen, sobre todo, los fervorosos danzantes. La fiesta de la virgen de Zapopan es la fiesta religiosa regional por excelencia.

\section{Entre ritualidad institucional y religiosidad popular}

La manera como se entiende, se vive y se practica la religión difiere, en muchos sentidos, entre la clerecía y los fieles laicos; entre el modelo "oficial" y la religiosidad popular. Esta diferencia se aprecia muy claramente en eventos como la romería, donde los fieles se organizan por su propia cuenta para realizar y perpetuar un ritual que se ha mantenido de generación en generación, pero siempre acompañados por los frailes franciscanos.

En las tradiciones de religiosidad popular predomina la subjetividad, la vivencia de la fe y la participación comunitaria; a ellas se opone la visión oficial de la jerarquía, que muchas veces pretende imponer, sin éxito, su propia visión de la práctica religiosa. La religiosidad oficial y la popular no están divorciadas ni completamente separadas. Una no puede expresarse sin la otra: ambas manifestaciones coexisten, al igual las actitudes mágicas y religiosas se mezclan continuamente entre 
sí en cualquier forma de religión. La primera trata de encauzar y la segunda de "desprenderse de ese carácter oficial" (Peraza, 2001, p. 7), dejar de lado las estructuras y desenvolverse de manera espontánea recreándose en cada acto.

La costumbre de danzar está en el origen mismo de la religiosidad en América Latina; es una de las manifestaciones religiosas prehispánicas que pasaron casi sin cambios a la religiosidad popular cristiana. (González, 2001, pág. 11) Por el contrario, para la jerarquía los momentos culminantes son los oficiales: la misa de despedida previa a la romería y que oficia el cardenal, y el recibimiento en el atrio de la basílica. Estos momentos son cubiertos ampliamente por los medios de comunicación y generalmente se aprovechan para difundir la opinión del cardenal acerca de un asunto importante de la política local o nacional.

El trabajo permanente de organización, así como la romería misma durante los cuatro meses y medio que dura su peregrinar en la zona metropolitana de Guadalajara, ha estado a cargo de los religiosos franciscanos, quienes se coordinan con los párrocos de los templos que visita. Los religiosos la acompañan en el traslado y el párroco se encarga del recibimiento y la fiesta durante su estancia. Los franciscanos tienen a su cargo la Guardia de Honor de la Virgen de Zapopan y la Banda de Guerra que están siempre presentes; llevan un registro de las danzas y les asignan el lugar que ocuparán en el cortejo.

\section{La Guardia de honor y la Banda de Guerra}

A diferencia de las danzas, que se organizan en colonias populares por iniciativa de los propios fieles, la Guardia de Honor y la Banda de Guerra han sido formadas y regidas por los religiosos y son, junto con las asociaciones eclesiales de laicos, los canales oficiales de integración de participantes, que han dado vida y conservan la tradición año con año.

La Guardia de Honor de la Virgen de Zapopan fue creada por el padre Gilberto Saldaña en 1942. A partir de ese año, la imagen ya no viaja en carroza sino en un automóvil que continúa jalado a través de gruesos cables, y la antigua costumbre de levantar arcos triunfales es sustituida por la de 
colocar arcos florales a los que se cuelga una granada, antes con palomas y actualmente con confeti. (González, 1999, págs. 50-51)

En la Guardia participan alrededor de 400 personas de ambos sexos y de todas las edades. Se turnan el cuidado de la imagen y el acompañamiento por días en grupos de 150 personas. Armando Ramírez comenta:

Para ser miembro de la Guardia se requiere asistir a unas pláticas que imparten los religiosos franciscanos en el convento de Zapopan, dos horas a la semana durante tres meses, y después se hacen votos. La Guardia tiene sus estatutos donde se especifican las funciones que cada miembro cubre en los tiempos de la romería. Los hombres se encargan de jalar el calabrote central que lleva la carroza y las mujeres y niños se ubican en la retaguardia cantándole y rezándole a la Virgen. Entre más tiempo se va participando más se va queriendo a María. En mi vida personal, desde que estoy en la Guardia, he recibido muchos favores que afianzan mi fe en ella. Hay más respeto y más responsabilidad en el trabajo. Hay quienes tienen 30 o 40 años en la Guardia. No es una obligación, es voluntario. No hay un requerimiento, no hay un pago, el único pago es estar cerca de la Virgen. Cada quien paga sus uniformes. (Ramírez, entrevista personal)

En el caso de las mujeres, comenta doña Poli, coordinadora de las señoritas

[...] si es casada le piden su acta de matrimonio y una carta de la parroquia. Cualquier persona puede entrar, pero llevando una vida recta. Yo entré a la Guardia desde niña, porque mis papás me traían. Ellos eran de la Guardia desde que la Virgen andaba en calandria, y le agarré amor a Nuestra Madre Santísima. Me ha hecho muchos favores. Ahora traigo aquí a unos nietecitos. Los domingos primeros de cada mes tenemos misa, junta y retiro. Los días 18 de cada mes hacemos una hora santa en el santuario. Es muy bonito. La nombraron Generala y la coronaron como reina porque ya no hay guerras. (Guzmán, entrevista personal)

La Banda de Guerra de la Virgen de Zapopan es un grupo que se forma dentro de la Guardia para acompañar las romerías con el toque de guerra. El sargento comenta: 
Yo estoy de sargento desde hace 20 años. Ingresé a la banda a la edad de 5 años. Hay ahorita 55 integrantes de ambos sexos. Las muchachas tienen de 15 a 18 años. Para entrar a la Banda primero hay que ingresar a la Guardia. Los cuatro meses y medio que peregrina la virgen andamos con ella. Los ensayos los hacemos de enero a mayo. Tenemos marchas especiales para la Virgen: el 3 de Diana, La Dragona, Las Margaritas, La Guadalupana, ipuros toques alegres para alegrar el ambiente! Todos trabajamos o estudiamos y nos damos tiempo para reunirnos. (Aranda, entrevista personal)

También ellos costean personalmente sus gastos como instrumentos y uniformes, y acompañan a la Virgen con mucho entusiasmo durante todos los trayectos.

\section{El mensaje oficial. El modelo de Iglesia.}

La romería, siendo como es, una movilización que congrega a millones de personas y a los principales medios de comunicación, suele aprovecharse para difundir los mensajes oficiales, entre ellos la versión de la historia de la imagen desde la perspectiva de la jerarquía. Por el altavoz del contingente de seminaristas se escucha: "Pacificadora fue llamada, porque estando ensañados los indios en larga y enconada lucha, y habiendo ya muchos muertos de ambos bandos, fray Antonio, con la imagen colgada al pecho, subió a donde estaban los indios, de ella salían celestiales luces, que obligaban a los indios a seguir a dicho padre. Él pudo establecer entonces la paz entre los contendientes..." de manera que, si bien el origen de la imagen no es milagroso, se difunde como tal el principio de su veneración, mostrándose precisamente a los indios ya vencidos por los conquistadores. Un mensaje en que se presenta a los indios como culpables de la cruenta guerra y se exculpa, sin más, a los conquistadores, quienes no aparecen en el discurso.

Desde la ritualidad "oficial" se ha pretendido quitar el carácter festivo con el cual nació la romería y que sigue atrayendo por sí sola y para sí millones de peregrinos que oran y danzan con fervor a la virgen taumaturga, recordando y recreando ese pasado indígena que no puede ser borrado de la historia. 


\section{Participación de las autoridades civiles. Costos.}

Haciéndose eco de aquellos acuerdos pactados en 1734, las autoridades locales continúan apoyando y vigilando la multitudinaria romería. Cada vez mejor organizada y con menos percances que lamentar, las brigadas de socorristas, paramédicos y bomberos auxilian año con año a los romeros. 2 500 comerciantes se instalan en el perímetro de la romería. La Dirección General de Servicios Públicos del Ayuntamiento de Zapopan implementa el Operativo Romería para recibir a los casi dos millones de peregrinos que acompañan a la Virgen de Zapopan a su basílica. El ayuntamiento costea los gastos de 250 sanitarios, 50 mil litros de agua potable, 40 centros de carga de energía eléctrica, camiones especiales para la vigilancia de la zona, cuadrillas de trabajadores que pintan machuelos, sanean las calles y balizan áreas especiales para el comercio e instalación de áreas de descanso para los miles de danzantes.

El Ayuntamiento de Guadalajara pone a disposición miles de elementos viales para patrullar la zona, así como otros tantos de la Dirección de Seguridad Pública. Su trabajo es impedir que se filtren personas alcoholizadas que puedan ocasionar problemas.

"Saldo blanco en la romería", reportan generalmente los diarios locales al día siguiente. El ambiente que se vive es de festividad familiar y fervor a la imagen. No hay riñas ni agresiones. Si bien es cierto que la vigilancia policial contribuye a ello, lo más importante es el fervor o simple curiosidad tranquila lo que motiva a los millones de romeros y espectadores a asistir a la peregrinación.

¿Cuánto cuesta realizar un evento como este? Los costos erogados por la institución eclesial son nulos. Los que destinan los ayuntamientos son en realidad mínimos para la magnitud del evento y están contemplados dentro del presupuesto oficial. Los gastos más importantes los realizan los miles de peregrinos de manera individual. Son ellos quienes pagan sus trajes, sus pasajes, sus comidas y bebidas. Como se trata de personas sencillas y que tienen ingresos mínimos, estos gastos les 
representan sus ahorros de todo el año. Para eso ahorran: para comprar y adornar sus uniformes y trajes, para pagar sus pasajes y poder danzarle a la virgen todo el tiempo posible.

7.- Un acto eminente de religiosidad popular, donde los danzantes son los grandes protagonistas.

Las danzas, al igual que las peregrinaciones, las mandas, los altares o las apariciones y revelaciones de mensajes divinos, son expresiones de la religiosidad popular que han existido a lo largo de la historia como una manera en que los hombres y mujeres establecen comunicación con lo divino y obtienen respuesta. A través de estas formas de la religiosidad popular se recrea y se asimila el alma de los pueblos; la doctrina se transforma en vivencia, en fuente de fe, en lenguaje divino que acerca a los hombres a Dios. La experiencia religiosa deja de ser un acto solitario para convertirse en una experiencia colectiva, donde la vivencia de la fe tiene preeminencia sobre la doctrina.

Como la religiosidad popular no puede estar normada por las instituciones eclesiales, aparecen en algunos momentos rasgos que parecieran denotar antagonismos entre la vivencia de la fe y el ritual institucionalizado; entre la religiosidad popular y el interés "oficial". En este contexto deben interpretarse tanto la participación festiva de los millones de fieles que acuden a la romería, como el intento oficial de "encauzar" y normar un evento que parecieran calificar de espectáculo profano o folclorista. Para los danzantes, sin embargo, esta festividad no implica rupturas con el mensaje evangélico, sino la recuperación de su pasado y su cultura en un evento religioso en el cual ellos son los protagonistas. Su participación no cuestiona los aspectos doctrinales del catolicismo, sino que les da un sentido más cercano a su experiencia de vida:

[...] la danza es como el motor que pone en movimiento al universo. El sol danza, la luna danza, la luz y las estrellas brincan. Todo danza a la Virgen y a la Virgen le encantan estas cosas... Yo no sabía danzar, ya estoy viejito, a mi edad... pero los compañeros me dijeron: no te preocupes, la Virgen te va a enseñar a danzar y te va a dar fuerza, porque la Virgen danza en nosotros a Jesucristo." (Vázquez, 2001, p. 38). 
¿Por qué danzan? "Por devoción a la Virgen", contestan casi todos. "Porque es un gusto que nos da venir a acompañar a la Virgen". "Vengo descalza porque es una promesa que le hice a la Virgen por un milagro muy grande que me hizo". "Para agradecerle, para pedirle salud, para que me vaya bien en la vida". Muchos por el mero gusto de danzar y porque experimentan emociones nuevas. Danzan por propia voluntad, año tras año. Se preparan con meses de anticipación, recibidos en el hogar del dirigente de la danza. Asisten familias enteras: padres jóvenes cargando a sus hijos pequeños, todos con el atuendo. Ancianos que llevan 35 ó 40 años danzando. Niños pequeños que a ratos danzan y a ratos duermen en su carriola. Hombres y mujeres descalzos. No se les nota el cansancio ni el dolor.

Aunque la romería no nació para ser espectáculo, es un llamativo evento donde confluyen todas las formas de expresión, las vestimentas, los colores, los movimientos y los sonidos. En la danza se ofrenda el cuerpo a través de movimientos rítmicos y acompasados; a través del baile con los pies descalzos o marcando el paso con suelas de metal y cascabeles. En penachos multicolores se expresa ese pasado indígena que se vive y representa sólo en los momentos de la danza; porque en la vida cotidiana, el occidente de México es una región donde prevalece lo criollo, y la cultura está fuertemente influenciada por la norteamericana, resultado de la globalización y los enormes flujos migratorios.

Las danzas que acompañan a la Virgen proceden de diversas colonias populares de la zona metropolitana de Guadalajara, organizada en cuarteles. El Cuartel 1 "Real Unión de Danzantes Autóctonos de Jalisco", el año 2001 registró 40 danzas con 4361 miembros. El cuartel 2 "Danzas Autóctonas de Zapopan", 47 grupos con 4220 danzantes, y el Cuartel 3 "Danzas Chimalhuacanas", ubicado en Tlaquepaque y Tonalá, 65 danzas y 5600 miembros. A estas cifras se suman además los grupos procedentes del Bajío, Querétaro, Guanajuato, Zacatecas, Estado de México, el Distrito Federal y Michoacán. Estas cifras suman 14181 danzantes y 162 grupos sólo en la zona metropolitana de Guadalajara, a los que habría que sumar los procedentes de otros poblados. Es difícil tener una cifra exacta de participantes, señala Fray Lucio Muñoz, Guardián del convento, porque además de los contingentes registrados muchos se suman a la romería de manera espontánea, incrementando el número de danzantes y el tiempo de recorrido. Esto es, sin embargo la naturaleza y el carácter de la 
romería, lo que motiva a participar a los fieles e invita a los millones de espectadores que van a observar a los llamativos danzantes (Muñoz, 2002). Aunque son los protagonistas de la romería, los danzantes tienen su día especial el 13 de octubre, cuando el atrio les pertenece y se les asignan tiempos y lugares para danzar e ingresar al santuario.

Los grupos "mexicanistas" o New Age se deslindan de este acto religioso católico. Ahora permanecen danzando, quemando incienso y sonando caracoles en el centro de la ciudad de Guadalajara y visitan antiguos centros ceremoniales en las fechas de equinoccio y solsticio. Buscan recuperar los rasgos autóctonos de nuestra cultura mestiza, influenciados por las ideas de Piña Chan y Carlos Castaneda. Son casi todos profesionistas de clase media que tienen un pasado católico pero cuestionan el papel de la jerarquía.

Las danzas foráneas establecen redes y hermandades con las de la zona metropolitana. Hay de varios tipos: de Concheros, de Sonajeros, de Matachines, de Conquista, Pieles Rojas, Negritos o Tastoanes. Tal vez las que más impresionan, por su atuendo y sus coreografías, sean las danzas aztecas y las de conquista. En ellas se representa la conquista española y se reinterpreta la evangelización, otorgando un lugar preponderante a los indios vestidos con trajes espectaculares. Españoles e indios marchan juntos al ritmo de los tambores y convocados por los caracoles, como muestra de la asimilación del mestizaje en la región. Algunas de estas danzas todavía conservan parlamentos donde aparece el santo Santiago, fundador de España y protector de los conquistadores; "Matamoros" en aquellas tierras y "Mataindios" en los pueblos americanos. Españoles e indios danzan juntos en ofrenda a la imagen pacificadora que entregara el franciscano Antonio de Segovia después de la guerra del Mixtón.

En las danzas de sonajeros, matachines y tastoanes, se representa la asimilación del pasado indígena del occidente de México, que ninguno de los entrevistados identificó como chichimeca u otomí, sino como "azteca" o "piel roja". Los sonajeros provienen de poblados del sur de Jalisco, donde todavía se reconocen como descendientes de indios. Los matachines, vestidos con trajes cubiertos de carrizos, provienen de Zacatecas y el norte de Jalisco. Se observan también grupos de huicholes o wixaritari vestidos con su atuendo tradicional, quienes a pesar de las dificultades para conservar su 
tradición y su costumbre, practican sus ceremonias ancestrales de culto al sol, a la madre tierra y al maíz.

Una gran cantidad de danzas se denominan aztecas, grupo prehispánico del centro de México que poco tiene que ver con nuestro pasado, pero que nos muestra también una visión centralista de lo indígena. En los nombres de estas danzas se utilizan los de los dioses en náhuatl y se añade muchas veces el de un santo católico.

En las danzas participan hombres y mujeres de todas las edades. Año con año van mejorando su traje añadiendo plumas multicolores o chaquiras y lentejuelas. Sin embargo, casi nadie conoce el origen ni el significado de su vestimenta. Para los Matachines de la Danza de Guadalupe, Zacatecas, cuyo atuendo se compone de un enorme sombrero cubierto de finas plumas multicolores, llamado "pizcarricho" y una falda cubierta con popotillos de madera llamada "hulla", su atuendo "es un vestido azteca con penacho". Acompañan su danza con tambores y flautas y de su sombrero cuelga una enorme cola de cerda de caballo. El traje lo diseña el capitán y lo renuevan cada dos años.

Los "Sonajeros de San Antonio" van vestidos con trajes de pieles rojas. También lo renuevan cada dos años siguiendo el mismo modelo. Al preguntarles qué significa su traje, explican: "Hace mucho tiempo estaban aquí los pieles rojas y de ahí retomamos la vestimenta."

Son en realidad datos irrelevantes para los danzantes que en nada modifican su deseo de participar en la ofrenda a la virgen; "nomás se necesitan las ganas". La apreciación de su danza y su vestimenta nos muestra la visión que en general se tiene del pasado y de lo "indígena", donde lo mismo da ser piel roja o chichimeca, tastoán o azteca. Todos son indios, todos tienen fe en la virgen, todos danzan y todos llevan plumas. Es el México profundo frente al México imaginario del que hablaba Guillermo Bonfil. La reinterpretación del pasado indígena como la unidad de culturas de toda América. La asimilación de todas las guerras en una sola (la del Mixtón, la cristera) que la virgen resuelve milagrosamente, y por eso es "pacificadora". Es la fiesta de los danzantes y los laicos unidos por una imagen, donde lo que menos importa es la presencia de la jerarquía.

\section{Referencias:}


Cardaillac, L. (2002). Santo Santiago. El santo de dos mundos. Zapopan: El Colegio de Jalisco.

González, A. (2001) Origen y desarrollo de la religiosidad popular en el mundo cristiano. Revista de Ciencias Religiosas. (4), enero-abril. 11-14.

González, A. (1999). Biografía de una tradición. Las visitas de Nuestra Señora de Zapopan a la Ciudad de Guadalajara de 1734 a 1999. Zapopan: UNIVA

Muriá, J.M. (1980). Historia de Jalisco, t. 1. Guadalajara: UNED

Peraza, L.H. (2001) Las ciencias sociales ante los fenómenos religiosos. Revista de Ciencias Religiosas. (4), enero-abril. 4-10

H. Ayuntamiento de Guadalajara. (1989). Reglamentos, ordenanzas y disposiciones para el buen gobierno de la ciudad de Guadalajara, 1733-1900. Vol. 1. Guadalajara: Archivo Municipal

Sánchez, L. (2018). Llegaron... se establecieron... cuándo fundaron?. En García, M. Zapopan, una historia entre siglos. Zapopa: H. Ayuntamiento de Zapopan. Fundación Biblioteca Virtual Miguel de Cervantes

Vázquez, L.C. (2001). Religiosidad e institucionalidad católica. Revista de Ciencias Religiosas. 2(4) eneabril. 36-40. 